\title{
Cuidado nutricional na visão de enfermeiras docentes ${ }^{1}$
}

\author{
Nutritional care from the nursing teacher's \\ point of view
}

Silvia Henrique de CAMPOS $^{2}$

Maria Cristina Faber BOOG ${ }^{3}$

\section{RE S U M O}

\section{Objetivo}

Identificar percepções e práticas de docentes de um curso de graduação em Enfermagem em relação ao ensino de nutrição, a fim de subsidiar propostas pedagógicas.

\section{Métodos}

A pesquisa foi realizada em uma universidade privada do Estado de São Paulo com a participação de treze docentes, empregando-se, em uma primeira etapa, metodologia qualitativa mediante o uso de questionário. Na segunda etapa, foi utilizada a técnica de grupo focal com a participação de cinco dessas docentes.

\section{Resultados}

O ensino de nutrição na graduação das enfermeiras docentes não contemplou as demandas da prática profissional. Elas consideram que houve um declínio na qualidade do cuidado nutricional, durante os últimos anos, e sentem dificuldades em relação a esse cuidado tanto no hospital como na área de saúde pública. Sentem dificuldade, também, para o trabalho em equipe.

\section{Conclusão}

A discussão em grupo criou um ambiente favorável à problematização da prática profissional do enfermeiro em relação ao cuidado nutricional, propiciando uma autocrítica no que diz respeito à parceria com outros profissionais da saúde. O ensino de nutrição deve contemplar temas como cuidar/cuidado e interdisciplinaridade para preparar melhor o aluno para a prática.

Termos de indexação: alimentação; docente de enfermagem; nutrição; saúde-educação; prática do docente de enfermagem.

\footnotetext{
1 Artigo elaborado a partir da dissertação de S.H. CAMPOS, intitulada "Subsídios para o ensino de nutrição em enfermagem: uma experiência usando a técnica de grupo focal". Departamento de Enfermagem, Faculdade de Ciências Médicas, Universidade Estadual de Campinas; 2002.

2 Curso de Nutrição, Faculdade de Ciências Biomédicas, Centro Universitário Nossa Senhora do Patrocínio. Itu, SP, Brasil.

3 Departamento de Enfermagem, Faculdade de Ciências Médicas, Universidade Estadual de Campinas. Caixa Postal 6111, 13081-970, Campinas, SP, Brasil. Correspondência para/Correspondence to: M.C.F.BOOG. E-mail:<crisboog@fcm.unicamp.br>.
} 
146 S.H. CAMPOS \& M.C.F. BOOG

\section{A B S T R A C T}

\section{Objective}

To identify the perceptions and practices of teachers from an undergraduate nursing course with respect to the teaching of nutrition, as a subsidy to pedagogical proposals.

\section{Methods}

The survey was carried out in a private university in the state of Sao Paulo with the participation of thirteen teachers, employing qualitative methodology by means of a questionnaire in the first stage. In the second stage, the focus group technique was employed with the participation of five teachers.

\section{Results}

The teaching of nutrition in the undergraduate courses of the nursing teachers did not contemplate the demands of professional practice. They consider there has been a decline in the quality of nutritional care in recent years and have difficulty with respect to such care both in the hospital and in the public health area. They also have difficulty with teamwork.

\section{Conclusion}

The group discussion created a propitious atmosphere for discussing the problem of the professional practice of nursing as related to nutritional care, propitiating self-criticism concerning their partnership with other health professionals. The teaching of nutrition should contemplate topics such as care/caring and interdisciplinarity so as to better prepare the student for practice.

Indexing terms: feeding; faculty nursing; nutrition; nursing faculty practice; health-education.

\section{N T R O D U Ç Ã O}

Pensar um ensino que atenda às necessidades atuais exige reflexão sobre novas abordagens, a fim de articular o conhecimento acadêmico com a realidade social. Vários educadores $^{1-4}$ têm trazido propostas para possibilitar uma reflexão sobre o processo educativo, nas quais perspectivas como holismo, transdisciplinaridade e complexidade são discutidas e têm se mostrado bastante apropriadas no que diz respeito ao ensino de nutrição, complexo e multifário, comportando temas de interesse atual como ecologia, ética, qualidade de vida e direitos humanos entre outros $^{5}$. O desafio é a articulação dos diversos saberes a fim de gerar mudanças no processo educativo e nas práticas profissionais. Dessa forma, no ensino de nutrição não devem ser considerados apenas os aspectos técnicos, mas também a cultura, que agrega experiências do cotidiano sobre o que é nutrição/alimentação, e que interfere na construção do saber.

Quando se considera o conhecimento de nutrição aplicado à prática profissional, surge a dúvida sobre a aplicação desse conhecimento na interface do trabalho de nutricionistas e enfermeiros em equipe multiprofissional, no qual o cuidado nutricional está presente. Estudos revelam que, na prática assistencial, não se dá a devida importância ao cuidado nutricional ${ }^{6-8}$, que envolve "o conjunto de medidas a serem tomadas a fim de prover ao paciente uma alimentação com finalidade terapêutica, que garanta o fornecimento adequado de nutrientes, previna a desnutrição e contribua para o controle do processo patológico e recuperação da saúde, proporcionando, ao mesmo tempo, o maior grau possível de satisfação sensorial e psicológica"9.

O cuidado ao paciente/cliente implica a ação de diferentes profissionais da saúde, e o trabalho conjunto exige que representantes de várias especialidades saiam do estatuto científico estreito para uma nova conformação de equipe, considerando o processo atual do trabalho em saúde. A enfermagem remete à tradição do cuidado geral do paciente no seu contexto cultural, social, emocional, aplicando um conhecimento aliado à afetividade para melhorar as condições gerais do indivíduo. 
No momento em que ocorrem grandes transformações nas sociedades globalizadas, nas quais os interesses se tornam mais técnicos do que humanos, mostra-se oportuno resgatar o cuidado humano ${ }^{10}$, como forma de melhor compreender os aspectos envolvidos na prestação do cuidado nutricional ao cliente/paciente e para relativizar a visão biologicista que tem sido predominante na área da saúde.

O cuidar/cuidado é um modo de ser, uma atividade humana mútua de ajuda que promove crescimento e auto-realização. Profissionais da área de saúde não diferem quanto ao objeto e ao sujeito do cuidar/cuidado, mas sim na forma como expressam cuidar/cuidado ${ }^{10}$.

No momento em que se repensa o conhecimento a fim de ter uma nova visão da realidade e proporcionar mudanças nas percepções, nos valores e na cultura, espera-se dos profissionais da saúde uma nova postura frente ao ensino. Exige-se uma prática que transcenda o saber gerado pela ciência e tecnologia, visando ultrapassar os limites já delineados pelas disciplinas. Uma proposta que tem sido discutida é a transdisciplinaridade, na busca de um novo paradigma para as ciências da educação e para outras áreas, como a da saúde.

Comumente observa-se que o momento da alimentação não é valorizado na assistência. Há necessidade de atendimento às individualidades, considerando que, no processo patológico, a alimentação tem um significado emocional tão importante quanto o terapêutico para o paciente, estando diretamente relacionada aos fatores socioculturais, étnicos, religiosos. A inapetência, a aceitação ou a rejeição dos alimentos também passam despercebidos. O Inquérito Brasileiro de Avaliação Nutricional Hospitalar ${ }^{8}$, realizado com 4 mil doentes internados nos hospitais da rede pública de doze estados e do distrito federal, revelou que $48,1 \%$ dos doentes internados encontram-se desnutridos, sendo que $31,8 \%$ dos pacientes já estão desnutridos nas primeiras 48 horas de internação, aumentando para 44,5\% em três a sete dias de internação, 51,2\% em oito a
15 dias, passando para $61,0 \%$ nos doentes internados há mais de 15 dias, o que levou os autores a concluírem que há "reduzida consciência das equipes de saúde quanto à importância do estado nutricional do paciente". Cabe à enfermagem, por meio do contato diário com o paciente, estar atenta a esses problemas e encaminhá-los ao nutricionista para implementação da prestação do cuidado.

A linha de pesquisa Ensino de Nutrição, Trabalho, Saúde e Educação do Programa de Pós-Graduação do Departamentos de Enfermagem, Faculdade de Ciências Médicas (Unicamp), na qual o presente trabalho se insere, tem por finalidade avaliar a natureza das demandas em relação ao ensino de nutrição na área de Medicina e de Enfermagem, bem como sua oferta e abordagem em diferentes instituições, buscando subsidiar a expansão e o aprimoramento desse ensino.

O propósito deste estudo foi identificar as percepções e práticas de enfermeiros docentes de um curso de graduação em enfermagem com relação ao ensino de Nutrição, a fim de levantar subsídios a propostas pedagógicas.

\section{MÉ T O D O S}

O estudo foi realizado com enfermeiros docentes do departamento de Enfermagem de uma universidade privada do Estado de São Paulo. A coleta de dados foi realizada em dois momentos. No primeiro, aplicou-se um questionário individual contendo perguntas fechadas e abertas, no qual obtiveram informações sobre o ensino de nutrição oferecido na graduação dos enfermeiros docentes e as práticas docentes atuais referentes a essa área do conhecimento. O total de enfermeiros docentes do departamento era 19, e 13 responderam ao questionário. No segundo momento, os sujeitos foram convidados a participar de uma discussão em grupo, sendo utilizada a técnica do grupo focal para aprofundar as respostas dadas pelos enfermeiros. Nessa etapa, cinco enfermeiros docentes aceitaram participar do grupo. 
As questões propostas foram elaboradas a partir do conhecimento prévio das experiências dos sujeitos acerca do ensino de nutrição, obtido por intermédio do questionário. As perguntas dirigidas ao grupo foram: o que significou o ensino de nutrição em sua formação de enfermeira? Qual foi o impacto, depois da formação, quando foram para a prática, com relação a este conhecimento obtido na graduação? O que vocês ensinam sobre nutrição aos alunos? O que é saúde para vocês e qual a relação de saúde com nutrição? O que é interdisciplinaridade para vocês? O que é "desarmar-se"?

A utilização de técnicas participativas tem se mostrado produtiva para a abordagem do indivíduo em suas relações cotidianas. O grupo focal foi escolhido por ser uma técnica empregada há alguns anos para a discussão de questões da área de saúde sob o ângulo do social, além de possibilitar a emergência de valores subjetivos que são importantes no que diz respeito tanto ao ensino como à nutrição e à alimentação.

O grupo focal permite a obtenção de dados de natureza qualitativa a partir de sessões grupais, em que pessoas que compartilham traços comuns discutem aspectos de um tema específico. A utilização da discussão em grupo proporciona "pensar coletivamente uma temática que faz parte da vida das pessoas reunidas, fazendo vir à tona percepções, atitudes e opiniões" 11 . O grupo focal tem sido utilizado na área da saúde pela facilidade de obtenção de dados, pois a discussão é centrada em um tema específico, possibilitando aprofundar as discussões em um curto período de tempo - de uma a três horas de duração, com grupos de 6 a 12 pessoas, podendo esse número variar. Os grupos focais são flexíveis, não havendo um roteiro rígido de questões ${ }^{11,12}$.

O universo de significados, percepções e valores emerge nas discussões grupais em decorrência da interação do grupo em determinado ambiente social, além de provocar reflexões que podem conduzir a um maior conhecimento e conscientização dos sujeitos a respeito da temática levantada ${ }^{13}$.
A análise dos dados foi qualitativa, empregando-se a técnica de análise de conteúdo que é definida como "um conjunto de técnicas de análise de comunicação visando obter, por procedimentos sistemáticos e objetivos de descrição do conteúdo de mensagens, indicadores que permitam a inferência de conhecimentos relativos às condições de produção/reprodução dessas mensagens"14. Procurou-se analisar as falas das enfermeiras docentes quanto à sua ação profissional, dentro do contexto institucional e das relações sociais nas quais ocorrem.

O encontro, que teve duração de três horas, foi gravado; posteriormente, foi feita a transcrição das fitas e realizadas a leitura e a releitura do material para a familiarização com os elementos emergidos das falas e que responderiam aos objetivos do trabalho, com o intuito de elaborar temas e subtemas que se transformariam em eixos aglutinadores das idéias centrais dos resultados.

\section{RES U LT A D OS}

O grupo era composto por cinco enfermeiras docentes, com idade entre 46 e 57 anos, com atuação nas áreas de reprodução humana e ginecologia, saúde coletiva, enfermagem médico-cirúrgica e administração em enfermagem. O tempo de docência na instituição variava entre 9 e 27 anos e todas se graduaram na mesma instituição em que trabalham. Nas discussões, todas as enfermeiras relataram dificuldades em lidar com situações do cotidiano no que diz respeito à nutrição.

As participantes do grupo focal manifestaram certo receio, no início, com relação à tarefa de aprofundar algumas questões levantadas no questionário aplicado na primeira etapa, mas, aos poucos, foram construindo um processo de discussão no qual puderam se confrontar com a complexidade do cotidiano profissional, que envolve posicionamentos éticos, morais e sociais frente aos desafios das questões ligadas à nutrição e à alimentação. 
O grupo mostrou-se mobilizado para a discussão, relatando, inclusive, ser prazeroso relembrar a vida acadêmica, como também a importância da disciplina em épocas posteriores, o que revela o estabelecimento de um vínculo positivo e até afetivo com essa aprendizagem, depreendido a partir de falas que expressaram o valor dos conhecimentos na vida pessoal e familiar.

A participação no grupo focal proporcionou às docentes oportunidade de refletirem sobre as dificuldades de inserção em espaço coletivo, em virtude da ausência de uma aprendizagem - desde a formação acadêmica até hoje como docentes do que é o trabalho em equipe. Isso se reflete no trabalho multiprofissional, no qual diferentes profissionais não têm clareza do papel de cada um no atendimento a pacientes/clientes:

Trabalhar em grupo, pra mim, eu tenho uma certa dificuldade [...] é uma questão que vem da formação [...].

Porque todo mundo tá querendo cuidar da alimentação, da nutrição do paciente. Todos têm um papel importante.

Nós não tivemos essa formação pra trabalhar em grupos no meu curso superior [...] a gente faz esses exercícios com os nossos alunos e muitas vezes não é bem-sucedida [...] a gente não trabalhou muito esta questão.

Apesar de reconhecerem a importância de cada profissional no cuidado nutricional, as enfermeiras ressentem-se de uma formação acadêmica tradicional, o que torna mais difícil o trabalho em parceria, necessitando, portanto, de um reaprender a trabalhar em equipe, implicando mudança de valores e de posicionamentos rígidos.

As docentes relataram que o ensino de nutrição foi deficiente e estritamente técnico, principalmente voltado à área hospitalar, não abordando temas relacionados à saúde coletiva:

O impacto pra mim foi quando eu vim trabalhar na faculdade porque eu trabalho na área de Saúde Coletiva, aquela coisa do social [...] eu não me senti preparada pra enfrentar estas situações da realidade.

Não foi sequer discutido no meu curso de nutrição, eu não me lembro porque eu sempre me identifiquei com saúde pública [...] eu me lembraria disso, me marcaria e não marcou [...] foi um curso muito técnico, nutrientes, dietas, essas coisas [...] a fome nem sequer foi discutida [...].

A abordagem estritamente técnica do ensino de nutrição acaba privilegiando conteúdos fortemente voltados à bioquímica, à fisiologia e à patologia, deixando de lado aspectos sociais. Essa formação faz com que o enfermeiro não consiga lidar com situações do cotidiano como também não permite que ele associe questões alimentares individuais com questões maiores, como aquelas ligadas à política econômica. É preciso criar espaços para discussão das questões sociais, a fim de que haja maior conscientização dos profissionais de saúde de que há limites para a sua atuação profissional perante os aspectos sociopolíticos que envolvem a nutrição.

\section{O cuidar e a alimentação}

As enfermeiras apontaram que houve um declínio na assistência ao cuidado nutricional, relatando experiências com a alimentação servida ao paciente:

Na minha opinião é uma questão relegada a planos, assim, bem distantes [...] esse convívio, esse prazer, a cultura, os costumes [...] tem que ingerir aquela determinada alimentação por conta de que faz parte do tratamento.

Isso (a alimentação) é menosprezado na prática. Geralmente muito poucos profissionais de saúde fazem uma prescrição, perguntar para o paciente: o que o senhor comeu? O que a senhora come?

Você vê o paciente passar fome porque ele não suporta a forma, a consistência 
da alimentação, quando dá pra seguir uma prescrição médica sem aquela consistência [...].

Aí a importância da enfermagem poder detectar [...] e encaminhar ao nutricionista [...], mas não tem em número suficiente" (o profissional da nutrição).

$\mathrm{Na}$ área de pediatria é pior ainda [...] as mães ficam junto, elas comem junto com a criança, não tem refeitório, não tem aquele prazer, né?

A gente trabalha num hospital-escola, tem que ser um hospital modelo!

As falas denunciam a falta de atenção às individualidades e o não reconhecimento da importância da alimentação no cuidado ao paciente, tanto por parte da instituição como da equipe multiprofissional. Além disso, quando há necessidade de dietas específicas para determinadas doenças, na percepção delas, não existe a preocupação com outros aspectos, como fatores emocionais e culturais, que interferem na aceitação do alimento pelo paciente. Levantam igualmente a deficiência do número de nutricionistas para o atendimento às necessidades individuais com relação à alimentação, situação que também é vivenciada em muitas instituições hospitalares nas quais o profissional é responsável, simultaneamente, pelo setor de produção e de atendimento clínico.

Fica evidente a insatisfação das enfermeiras quanto à qualidade da alimentação servida, aspecto que transcende o seu limite de ação. Enfatizaram ainda serem inaceitáveis as situações descritas, levando-se em conta o fato de ser um hospital universitário, no qual atuam vários alunos dos diferentes cursos da área de saúde da instituição. A dietética e a dietoterapia não podem estar dissociadas, pois a alimentação está diretamente relacionada a fatores culturais e emocionais, além dos aspectos individuais relativos à história alimentar e à personalidade ${ }^{5}$. Em um dos casos citados, pelo fato de o paciente ser uma criança, outros fatores estão envolvidos, principalmente o emocional, tanto em relação à própria doença como em relação à impotência da mãe ante a situação.

\section{Papel do enfermeiro no cuidado nutricional}

As enfermeiras relataram que a atenção com o cuidado nutricional foi se perdendo ao longo dos anos e uma delas apontou que em épocas anteriores havia uma preocupação maior quanto aos cuidados no oferecimento da dieta aos pacientes:

Os professores se preocupavam muito: olha, vocês precisam observar como enfermeiras [...] que esta alimentação não chegue gelada [...] existia uma preocupação maior de não estar só nutrindo [...].

Passaram a traçar um paralelo entre o passado e o presente na atuação do enfermeiro. Falaram sobre as atribuições que tinham e o quanto foram se afastando da relação com o paciente, dando maior ênfase às questões técnico-administrativas e também à perda das suas atribuições para outros profissionais, que foram sendo agregados à equipe, como o assistente social e, principalmente, o nutricionista. Para o grupo, tais mudanças acabaram gerando uma certa acomodação profissional:

[...] a preocupação se ele não pudesse comer sozinho, a gente deveria estar presente, a enfermagem deveria estar presente, ajudando, incentivando [...].

as funções, as atribuiç̧ões foram diluídas, certo? Apareceu o assistente social, então muitas das coisas que $o$ assistente social hoje faz, nós tínhamos que fazer [...] e a enfermeira também se acomodou em pequenas outras funções [...].

Retomaram o papel do enfermeiro no acompanhamento da aceitação da dieta, bem como do estado nutricional do paciente, uma vez que é a enfermagem, por meio do contato diário com o paciente, que tem melhores condições de detectar uma inapetência.

A enfermagem ainda tem esse papel [...] colher dados junto ao paciente [...] eu não sei o que aconteceu, acho que houve um afastamento, ficou mais impessoal, hoje não se preocupa com esta questão [...] talvez com coisas mais técnicas [...]. 
Porque na visita diária, aquele contato e aquela relação mais próxima com o paciente permite uma abertura maior em relação a outras questões.

Num momento crescente de problematização, as docentes interrogaram-se sobre o papel do enfermeiro no cuidado nutricional, quais suas responsabilidades e qual o posicionamento de cada um dentro da equipe profissional e não chegaram a uma resposta diante das indagações. A grande transformação do trabalho em saúde trouxe as especializações, e a hiperespecialização impede a concepção de conjunto, evidenciada na falta de integração do trabalho dos diferentes profissionais ${ }^{3}$.

As enfermeiras afirmaram que, além da falta de atenção dos profissionais envolvidos no atendimento ao paciente, a estrutura da instituição, no caso o hospital, não permite que se ofereça melhor qualidade na alimentação:

[...] às vezes o pão vem sem um papel, sabe? É colocado o pão em cima do copo de café [...] não existe a mínima apresentação [...] não basta você falar que é pouco [...] você pede pro paciente falar, você pede pro médico, até que tudo seja providenciado, já passou uma semana [...] por causa das regras.

Três questões são apontadas: o descaso com a alimentação, a inflexibilidade para adaptações da dieta e o fator econômico. A alimentação oferecida é um serviço prestado pela instituição, em relação ao qual não são levadas em conta as singularidades do paciente nem a sua percepção sobre esse serviço9.

\section{I S C U S S Ã O}

Os aspectos que ficaram mais evidentes nos resultados foram a dificuldade de lidar com as questões sociais da alimentação, a percepção do declínio no cuidado e a dificuldade de trabalhar em equipe.

O primeiro guarda relação com o projeto pedagógico do curso ou da universidade, uma vez que instituições de ensino que têm como proposta proporcionar um ensino crítico que ofereça oportunidades de o aluno entrar em contato com a realidade trabalharão melhor essa questão, possivelmente também na área de nutrição. Especificamente na área de enfermagem, encontram-se trabalhos ${ }^{15}$ que buscaram explicitar a contribuição do pensamento pedagógico de Paulo Freire à prática e educação críticas.

Em relação ao declínio do cuidado observa-se a insatisfação com as ações desenvolvidas em relação ao cuidado nutricional, porém essa insatisfação não chega a resultar em idéias, sugestões ou ações para aprimorar a prestação desse cuidado. Quando as docentes dizem que a alimentação é "uma questão relegada a planos bem distantes" e que ela é "menosprezada na prática", elas expressam a percepção de que a despeito dos avanços científicos, o cuidado não se efetua a contento. Há um grande número de trabalhos científicos na área de nutrição tratando aspectos técnicos, porém há muito poucos discutindo a qualidade do cuidado nutricional em si, independentemente da intervenção técnica. Há que ter uma preocupação com a qualidade desse cuidado nutricional, mesmo quando o estado do paciente não exige qualquer intervenção dietoterápica.

O terceiro aspecto - a dificuldade de trabalhar em equipe - poderia ser um dos fatores que impedem o aprimoramento do cuidado. $\mathrm{Na}$ medida em que o cuidado é transdisciplinar por natureza, a sua consecução não pode prescindir da interação entre os profissionais e da busca conjunta de soluções.

Em estudo realizado com alunos do quarto ano de um curso de enfermagem, verificou-se que, na percepção dos alunos, os enfermeiros são aqueles que prestam o cuidado ao doente como um ato mecânico, burocrático, descontínuo, desumanizado, submisso ao poder médico, centrado na doença e na técnica ${ }^{16}$.

A Organización Panamericana de la Salud ${ }^{17}$ ressalta a necessidade de incrementar a flexibilidade do currículo acadêmico e seu caráter interdisciplinar. Propõe também que tais 
modificações devem acompanhar uma redefinição das tarefas e responsabilidades dos enfermeiros, sem se afastar de sua função essencial. Nota-se, portanto, a preocupação de um organismo internacional em adequar a formação acadêmica diante das transformações por que passa o setor da saúde. Nessa mesma linha, Cutler ${ }^{18}$ recomenda que o ensino de nutrição para enfermeiros seja constantemente reavaliado para suprir as necessidades desse profissional em diferentes áreas e funções, em constante mutação. Já Lindseth $^{19}$ aponta uma inadequação dos conteúdos atualmente ministrados às necessidades requeridas na prática profissional.

Apesar de as docentes referirem que o ensino de nutrição foi significativo, verificou-se que essa avaliação foi muito mais voltada para a aplicação dos conhecimentos na vida pessoal. Os relatos revelam que houve uma lacuna, pois o conteúdo da disciplina foi estritamente técnico, não abordando temas sociais, não preparando o docente para o enfrentamento de questões relacionadas à nutrição e à alimentação em contextos populacionais específicos. Isso pode ser explicado pela visão que comumente se tem a respeito da nutrição, uma ciência baseada em processos químicos e fisiológicos, desvinculada da filosofia, da ética, das questões sociais e não entendida como uma área de conhecimento multifacetada, que exige abordagem integrativa com outras áreas. A ênfase atual no tema da segurança alimentar e nutricional pode contribuir para modificar essa tendência, entretanto é preciso direcionar o ensino para essa temática.

A posição da Associação Americana de Dietética $^{20}$ aponta que o ensino de nutrição é essencial na grade curricular dos profissionais de saúde para que eles tenham conhecimentos básicos e habilidades para identificar problemas nutricionais latentes, como também avaliar a necessidade de encaminhar o paciente para o nutricionista. Weigley ${ }^{21}$ e Warber et al. ${ }^{22}$, em estudos realizados com enfermeiros, corroboram esse posicionamento e consideram ainda que o nutricionista é o profissional qualificado para identificar os aspectos mais gerais da nutrição, que são fundamentais para a atuação inicial dos enfermeiros

Para que o conhecimento em nutrição tenha significado, é necessário que a abordagem transponha os limites da sala de aula, antecipando os problemas que serão vivenciados pelo aluno na prática, de forma a "reinventar o conhecimento" a partir de situações concretas da realidade social. Nesse sentido, a problematização mostra-se oportuna "para superar a visão mágica por meio de uma visão crítica partindo para a transformação do contexto vivido" ${ }^{23}$. A sociedade cobra a solução de problemas imediatos e a universidade deve assumir a responsabilidade de ser um instrumento humanizador e conscientizador para que o aluno tenha maior sensibilidade em relação aos problemas do cotidiano, a partir de uma apreensão profunda da realidade, o que the permitirá, então, transformá-la e recriá-la. Tal transformação é possível à medida que o docente passe a refletir sobre sua prática pedagógica, e que o ensino torne o aluno agente da transformação, na concepção de "educação libertadora", baseada na relação horizontal entre educador e educando, numa vivência solidária e interdisciplinar ${ }^{2,15}$.

Na visão das enfermeiras, a maneira como as questões relativas à alimentação são trabalhadas traduz o desrespeito às individualidades, tanto por parte dos profissionais responsáveis pelo seu fornecimento quanto pelo próprio hospital, e uma certa acomodação na atuação do enfermeiro que, apesar de reconhecer o seu papel no cuidado nutricional e saber que a negligência no acompanhamento da conduta alimentar do paciente pode afetar o seu estado nutricional, não age concretamente para transformar essas situações. Outros estudos ${ }^{6,7}$ realizados com enfermeiros e médicos também constataram que esses profissionais reconhecem que, apesar de a alimentação não poder ser descuidada, ela não é valorizada no tratamento do paciente. Essa conduta dos enfermeiros é analisada por Perry em dois estudos. Diz essa autora que ao lado da falta de conhecimento, há falta de comunicação e de coordenação, que são necessárias às boas práticas $^{24}$, e que há uma discrepância entre as 
atitudes em relação ao objeto nutrição/alimentação e as ações em relação aos mesmos ${ }^{25}$. A questão é tão complexa que essa autora valeu-se da expressão a hard nut to crack para explicitar a dificuldade de aplicar na prática os conhecimentos de nutrição.

As enfermeiras também ressaltaram que há um "descomprometimento" com o cuidar/cuidado, decorrente do distanciamento na relação profissional-paciente e do direcionamento de sua atuação profissional para questões técnico-administrativas, e interrogaram-se sobre qual seria o seu papel na equipe multiprofissional quanto ao cuidado nutricional. Considerando que o tratamento da doença é realizado preponderantemente na perspectiva biológica de saúde, o campo das relações interpessoais não é valorizado no que diz respeito ao cuidar/cuidado. As inovações tecnológicas produzidas nas últimas décadas geraram muitas transformações na área da assistência, e, apesar de trazerem grandes avanços no campo terapêutico, também contribuíram para a perda da formação humanista dos profissionais de saúde ao privilegiarem o direcionamento da atuação profissional às questões técnicas, administrativas e organizacionais.

Os profissionais preocupam-se em executar uma rotina sem, muitas vezes, ouvir o paciente, ocasionando episódios como o descrito por uma das enfermeiras - "você vê o paciente passar fome porque ele não suporta a consistência da alimentação...". A prescrição deve justificar as ações recomendadas ao paciente baseada no diagnóstico, mas, sempre que possível, referenciada, ou seja, "olhar" para o modelo teórico, "olhar" para o indivíduo em suas singularidades e praticar a assistência, considerando outros aspectos imbricados na conduta terapêutica, como o estado emocional do paciente, sua cultura e sua história de vida. Essa afirmação se aplica tanto aos enfermeiros quanto aos nutricionistas que, muitas vezes, exercem os seus papéis distantes do paciente.

Christensson \& Unosson ${ }^{26}$ também observaram que há pouca atenção da equipe de enfermeiros ao acompanhamento da alimentação e do estado nutricional dos pacientes. Em estudo realizado pelos autores, verificou-se que apesar da implementação de um programa de educação nutricional aos enfermeiros, não houve mudança nas atitudes desses profissionais em relação ao cuidado profissional.

Boog $^{27}$ sugere que as dificuldades encontradas na prática em relação à nutrição decorrem da complexidade do problema em si e dos conflitos que emergem das contradições entre o que se sabe e o que se pensa, com o que se sente e se faz na prática. Soares ${ }^{7}$ observou que para médicos residentes há uma lacuna entre a teoria ensinada e a prática clínica, porque eles detêm um conhecimento técnico, porém sua aplicação permeia questões do cotidiano e aí eles encontram dificuldades para lidar com tais questões; além de faltar um conhecimento mais contextualizado, parece faltar também, em relação à nutrição, o cuidado propriamente dito.

Entre as várias teorias que têm aprofundado o fenômeno do cuidar/cuidado no campo da enfermagem, a primeira e grande contribuição surgiu com a teoria transcultural, proposta por Madeleine Leininger, nos anos 60, como contraponto ao modelo positivista que norteava o conhecimento em enfermagem para a técnica e o tratamento, visando à cura. Para a autora, o cuidado é cultural, pois cada povo tem seu próprio modo de cuidar e se cuidar. Portanto, o cuidado deve ser significativo e eficaz às pessoas, de acordo com seus valores culturais e no contexto saúde-doença ${ }^{28}$, o que pode constituir o arcabouço das ações não só do enfermeiro, mas também de outros profissionais.

Quando se pensa no cuidar/cuidado, a referência é a enfermagem, mas, na área da saúde, o cuidar perpassa todos os profissionais que compõem a equipe, tanto na área hospitalar como na área de saúde pública. O cuidar/cuidado deveria ser abordado também na formação do nutricionista, de forma a incorporar a ciência/arte do cuidar na conduta profissional.

O cuidado é um aspecto que remete à transdisciplinaridade, pois implica novos modos de organização do conhecimento, ultrapassando fronteiras tradicionais de sua divisão por disciplinas fechadas. 
É preciso maior conscientização por parte dos profissionais de saúde acerca da importância do cuidado nutricional adequado para uma evolução clínica apropriada. Para tanto, além dos conhecimentos em nutrição, torna-se imprescindível que os profissionais tenham clareza de seus papéis e responsabilidades nas condutas relativas ao processo do cuidado nutricional. A avaliação do estado nutricional - que pressupõe, entre outros procedimentos, a pesagem do paciente e a observação da aceitação da dieta e sua correlação com a evolução do estado nutricional - é de grande importância e pode ser realizada pelos enfermeiros.

Na abordagem de problemas cotidianos, presentes no dia-a-dia dos profissionais responsáveis pelo cuidar/cuidado, há que compreender melhor o paradigma da complexidade ou o pensamento complexo, para associar as partes sem tirar a identidade delas. Portanto, nessa concepção, a unidade do conhecimento necessária na abordagem das questões relativas à nutrição e alimentação exige dos profissionais humildade e abertura pessoal, ou seja, um olhar disciplinar mas com a necessidade de sair de posições fixas para ampliar a visão e lidar com as incertezas ${ }^{4}$ do conhecimento inerentes às questões relacionadas à saúde. Para tanto, os profissionais devem ter clareza acerca da complexidade e interpenetração dos fenômenos relativos à alimentação e à nutrição, que imbricam questões bioquímicas, fisiológicas, emocionais, psicológicas, culturais, sociais, ecológicas, interferindo na relação dos seres humanos com a alimentação, individual e coletivamente.

\section{CONCLUSÃ O}

A maioria dos trabalhos encontrados na literatura relativos ao ensino de nutrição para enfermeiros foi composta de estudos do tipo survey, que se mostraram insuficientes, pois abordam, preponderantemente, o conhecimento. Nesse sentido, as autoras consideram que a metodologia escolhida neste estudo trouxe contribuição inovadora, pois a discussão favoreceu a problematização da prática profissional e a emergência de alternativas de temáticas para discussão.

Há necessidade de estratégias formais para integração do trabalho de enfermeiros e nutricionistas ${ }^{29}$, porém, no âmbito acadêmico, é necessário ousar e introduzir propostas pedagógicas que tragam real significado ao aluno. A metodologia problematizadora e a discussão de temas como cuidar/cuidado e interdisciplinaridade, durante o curso de graduação, constituem medidas viáveis para aprimorar o ensino e preparar melhor o aluno para lidar com os problemas na prática cotidiana, que vão além daquilo que o conhecimento técnico-científico aborda. Trata-se de aprender a lidar com nutrição/alimentação tal como essas questões se apresentam na vida cotidiana e na assistência, o que inclui relações entre os diferentes profissionais que compõem a equipe e a incorporação do cuidar/cuidado na alimentação/nutrição, superando a visão centrada apenas no conhecimento técnico-científico. Outros caminhos que se apresentam possíveis de serem colocados em prática são inserir temas de nutrição na educação continuada; criar instâncias formais de trabalho conjunto, por meio de projetos e de reuniões das quais participem vários profissionais; discutir ementas, objetivos e programas de nutrição procurando averiguar como se podem criar canais efetivos de interdisciplinaridade; propor atividades complementares que propiciem ao aluno um contato prévio com a comunidade com a qual ele vai lidar nos estágios curriculares.

Para um ensino de nutrição pertinente, devem-se levar em conta os novos paradigmas propostos para um processo educativo transformador da realidade. O espaço formal de ensino deve proporcionar uma religação com a vida de forma que o ensino não só atenda às necessidades da prática profissional, mas traga questões da realidade social para o espaço acadêmico.

\section{A GRADECIMENTO}

A assistente social e psicanalista Maria Auxiliadora Alves Cordaro Bichara, pela coordenação do grupo focal, que propiciou uma agradável e produtiva experiência interdisciplinar. 


\section{REFERÊ N CIAS}

1. D'Ambrosio U. Transdisciplinaridade. São Paulo: Palas Athena; 1997.

2. Freire P. Pedagogia da autonomia: saberes necessários à prática educativa. 13.ed. São Paulo: Paz e Terra; 1996.

3. Morin E. A cabeça bem feita. Rio de Janeiro: Bertrand Brasil; 2001.

4. Morin E. Os sete saberes necessários à educação do futuro. São Paulo: Cortez; 2001.

5. Boog MCF. Considerações sobre o ensino de nutrição nos cursos superiores da área de saúde. Rev Nutr. 1999; 7(1):23-30.

6. Boog MCF, Silva JB. Percepções de enfermeiras sobre o processo de cuidado nutricional. Rev Bras Nutr Clin. 2001; 16(1):17-22.

7. Soares FPTP. Abordagem de nutrição no curso de graduação de médicos residentes de cirurgia: subsídios para o ensino [dissertação]. Campinas: Universidade Estadual de Campinas; 2001.

8. Waitzberg DL, Caiaffa WT, Correia MITD. Inquérito Brasileiro de Avaliação Nutricional Hospitalar (Ibranutri). Rev Bras Nutr Clin. 1999; 14(2):124-34.

9. Boog MCF. O papel do enfermeiro no cuidado nutricional ao paciente hospitalizado. Rev Campineira Enf. 1999; 2(1):17-21.

10. Waldow VR, Lopes MJM, Meyer DE. Cuidar/cuidado: o domínio unificador da enfermagem. In: Waldow VR, organizador. Maneiras de cuidar, maneiras de ensinar: a enfermagem entre a escola e a prática profissional. Porto Alegre: Artes Médicas; 1995. p.7-30.

11. Westphal MF, Bogus CM, Faria MM. Grupos focais: experiências precursoras em programas educativos em saúde no Brasil. Bol Ofic Sanit Panam. 1996; 6(120):472-82.

12. Leopardi MT, Beck CLC, Nietsche EA, Gonzalez RMB. Metodologia da pesquisa na saúde. Santa Maria: Pallotti; 2001.

13. Minayo MCS. O desafio do conhecimento: pesquisa qualitativa em saúde. São Paulo: Hucitec; 1999.

14. Bardin L. Análise de conteúdo. Lisboa: Edições 70; 1979.

15. Miranda KCL, Barroso T. A contribuição de Paulo Freire à prática e educação crítica em enfermagem. Rev Latino-Am Enf. 2004; 12(4):631-5.

16. Chiarelli MQ, Mishima SM. A formação do enfermeiro crítico-reflexivo no curso de enfermagem da Faculdade de Medicina de Marília - FAMEMA. Rev Latino-Am Enf. 2003; 11(5):574-84.

17. Organización Panamericana de La Salud. Nuevos retos en el campo de la educación avanzada des personal de enfermería en America Latina. Rev Panam de Salud Publ. 1997; 2(1):51-6.

18. Cutler L. Nutrition education in baccalaureate degree nursing schools. J Am Diet Assoc. 1986; 86(7):932-7.

19. Lindseth $G$. Factors affecting graduating nurse's nutritional knowledge: implications for continuing education. J C Contin Educ Nurs. 1997; 28(6): 245-51.

20. Position Paper of the American Dietetic Association: nutrition education for health care professionals. J Am Diet Assoc. 1998; 98(3):343-6.

21. Weigley ES. Nutrition in nursing education and beginning practice. J Am Diet Assoc. 1994; 94(6):654-6.

22. Warber JI, Warber JP, Simone KA. Assessment of general nutrition knowledge of nurse practitioners in New England. J Am Diet Assoc. 2000; 100(3): 368-70.

23. Gadotti M. Um legado de esperança. São Paulo: Cortez; 2001. Coleção Questões da Nossa Época, 91.

24. Perry L. Nutrition: a hard nut to crack. An exploration of the knowledge, attitudes and activities of qualified nurses in relation to nutritional nursing care. J Clin Nurs. 1997; 6(4): 315-24.

25. Perry L. Fishing for understanding: nurses knowledge and atittudes in relation to nutritional care. Int J Nurs Stud. 1997; 34(6):395-404.

26. Christensson L, Unosson M, Bachrach-Lindström $M$, Ek AC. Attitudes of nursing staff towards nutritional nursing care. Scand J Caring Sci. 2003; 17(3):223-31.

27. Boog MCF. Dificuldades encontradas por médicos e enfermeiras na abordagem de problemas alimentares. Rev Nutr. 1999; 12(3):261-72.

28. George JB. Madeleine Leininger. In: George JB. Teorias de enfermagem: os fundamentos para a prática profissional. Porto Alegre; 1993. p.286-99.

29. Boog MCF. Construção de uma proposta de ensino para curso de enfermagem. Rev Nutr. 2002; 15(1):15-28.

Recebido em: 5/12/2003

Versão final reapresentada em: 7/1/2005 Aprovado em: 31/1/2005 